\title{
Innovation and its importance in the context of a company's marketing strategy
}

\author{
Veronika Olexova ${ }^{1, *}$ and Martina Gogolova ${ }^{1}$ \\ ${ }^{1}$ University of Zilina, Faculty of Operation and Economics of Transport and Communications, \\ Department of Economics, Zilina, Slovak Republic
}

\begin{abstract}
The current business environment is characterized by high competition between companies as well as global challenges and growing technological progress. Businesses must constantly adapt to changes in the business environment, changes in the market environment and the constantly changing requirements of customers. There are currently several tools and ways to respond to these changes. One of the most important areas can be considered corporate strategy, because it determines the basic direction of the company. An important area is also marketing, which affects the overall business activity. Determining the right marketing strategy has an important impact on the overall direction of the company. Another important element of the current time in the field of business is innovation, which can be considered a basic prerequisite for the success of the company. The issue of innovation management is currently one of the basic conditions for maintaining a market position and maintaining competitiveness. The aim of the article is to point out the theoretical basis of the corporate strategy, marketing strategy and the importance of innovation in business. Subsequently, based on secondary findings, we analyze available selected data related to innovation in Slovakia.
\end{abstract}

Keywords: company, innovation, marketing, strategy

\section{Introduction}

The ever-changing conditions in today's global world create a complex environment for companies, to which the company must constantly respond. In recent years, the business environment has undergone significant changes. That is why one of the key factors for success is a quick response to market changes. The company must be able to respond quickly to market and customer requirements. The aim of every company is to achieve success and maintain and improve its market position. It is essential that the company is constantly looking for new customers, but also to maintain and strengthen the relationship with the company's existing customers [1]. The economy is constantly undergoing significant changes, the role of the company is to anticipate these changes if it wants to move ahead of the competition. The means of this are innovation strategies and the rapid introduction of innovation into all business activities of the production process. Every business that wants to be successful in the long term needs an innovation management

*Corresponding author: veronika.paurova@fpedas.uniza.sk 
system [2]. It is therefore essential for businesses to have a well-defined long-term strategy that takes innovation into account. Company can suggest an appropriate marketing strategy that can bring it new customers [3]. At present, innovation is considered an important condition for competitiveness, which is a key strategic factor in economic performance. The importance of corporate strategy and marketing strategy should be a priority for companies. Marketing strategy is concept of a business venture in the field of marketing, that task is the allocation of resources enterprise with the aim of meeting the fundamental objectives of the company and to make a profit and competitiveness and achieve customer satisfaction [4]. The established strategy is then transformed into basic marketing elements, such as product policy, communication with target customers, pricing and distribution. Strategy setting is a continuous process that must adapt to changing market conditions. Innovation is now considered a prerequisite for a company's competitiveness [5]. Innovation is an important tool for business growth [6]. Implementing and creating innovation is a way in which a company can respond to the requirements of customers and the market itself, and thus ensure change in the company. Innovation is a process where the result is something new. With legal response to the market, an innovative approach and adaptation to market conditions lead to satisfied consumers, which are the foundation of a company's success. Innovation is the key to the success of many sectors of the economy [7].

\subsection{Marketing strategy of the company}

Strategy is the way in which a company achieves its goals [8]. It is the long-term intention of the organization that affects the current position [9]. The strategy expresses basic ideas about how long-term corporate goals should be achieved. The use of the company's resources and the course of individual strategic operations, which have the task of achieving the fulfillment of individual corporate goals, are part of the company's strategy. One of the specific areas of business strategy is marketing strategy. A marketing strategy is a process or plan that is used to achieve a company's marketing goals. Strategic direction is important for marketing managers [10]. Marketing strategy is the way a company achieves its marketing goals. It consists of decisions on marketing costs, the marketing mix and the allocation of marketing resources in relation to expected competitive conditions. [11]. The marketing strategy is also deciding on the program for the development of individual products and services, on the method of their sale, on the production and sales program and on the development of all components of the marketing mix [12]. Marketing strategy can be considered as the most complex tool of marketing strategic management, because its role is long-term operation and taking into account internal and external conditions in order to achieve the expected market position [13]. The marketing strategy is elaborated in detail in sub-strategies, which include product strategy, pricing strategy, distribution strategy and marketing communication strategy. The process of building and managing brand value should be part of the strategic marketing of every business [14]. The marketing strategy forms the basis for the development of the company's plans and the process of creating and maintaining a strategic balance between its goals and capabilities. The basis of the marketing strategy is the definition of the company's mission, determination of the company's goals, creation of a business portfolio and coordination of marketing and other functional strategies. Marketing strategy is a tool by which a company achieves its set marketing goals. The marketing strategy should also address the market segments that the company intends to focus on and focus on. The strategy that the company adopts is reflected in the design and development of the product, in the product policy, in the choice of the target market, in the subsequent communication with the target group, in the pricing policy and in the choice of distribution channels. Creating an optimal marketing strategy is 
not a one-time activity, but a continuous process. A strategy that has been successful in its time, or is currently successful, must constantly adapt to changing market conditions. The company must be able to understand consumer behavior and motivation to buy a product [15]. A strategic analysis that shows the situation of the company is necessary for the development of a quality company strategy. In general, strategic analyzes can be divided into internal analysis and external environment analysis [5]. The basic strategic analysis includes, for example SWOT analysis, EFE and IFE matrix, Porter's analysis of the five forces, PEST analysis, BCG matrix.

\subsection{Innovation}

Innovation is new developmental changes which the company apply in practical activities [5]. Innovation is the foundation of sustainable growth in the business and important source of competitiveness, economic growth, as well as the image of each country [16]. Innovation is a process from idea, through development to implementation. The term innovation can be understood as the introduction of a new or possibly significantly improved product or service on the market. The same applies to the process, i.e. the introduction of a new or significantly improved process within the company. Innovation is obtained through new or existing company technologies, or also using company knowledge. Innovation can be developed by a company or other companies and should represent a new change for the company. In the past, non-technological innovation, which has been based on experience, has predominated, but at present technological innovation is being applied [5. The result of an innovation is an improvement in a product, service or process, or anything else. Innovation is one of the most important factors influencing consumer attitudes [17]. Innovation can be technological or non-technological in nature. Technological innovation represents product innovation, ie. new or significantly improved product (product, service) introduced to the market or process innovation, a new or significantly improved process introduced within the company. Non-technological innovation includes organizational innovation and marketing innovation [18]. A product innovation is the launch of a new product (product or service) whose characteristics, or intended use, differ significantly from previous products. This includes new or significant changes to technical specifications, components and materials, embedded software, user acceptability (accessibility) or other functional characteristics. Innovation help business to extend the development of new products [19]. Process innovation is the introduction of a new or improved production method, logistics, supply and distribution systems. This includes significant changes to specific techniques, equipment or software that are designed to improve the quality, efficiency or flexibility of production or supply activities, or to reduce environmental or safety risks. Organizational innovation is the introduction of significant changes in business practice, the organization of work responsibilities and decision-making, which includes training or education to increase qualifications and responsibilities; and in the organization of external relations with other undertakings or public institutions. Their goal is to improve the innovative capacity of the company or performance characteristics, such as. quality and efficiency of workflows. Organizational innovation usually involves changes in more than one part of a company's supply chain and are less technology dependent than process innovation. Marketing innovation represents significant changes in the way products and services are traded, including changes in design and packaging. Many of them are included only in the first use by companies, for example the first use of the Internet for product placement is an innovation, but the second use of the Internet for the placement of other products, or. in various geographic markets it is no longer an innovation [18]. An important marketing tool is the brand, which is a key factor in changing the perception of competing brands [20]. In relation to customers, CRM (Customer Relationship Management) has an 
important position, which is defined as a marketing strategy that integrates technology, process and all business activities around the customer [21]. Innovation also plays an important role in this area. In connection with the innovation have an important role employee. Correcting executive stocks can stimulate innovation as well as meet employee expectations and needs [22]. Among the tools to support innovation, primarily by the state, we include state support. Support for innovation takes the form of a targeted subsidy from public sources. Funds are provided from the budget chapter of the Ministry of Economy. Other sources of support for innovation include the European Union Structural Funds for co-financing innovative projects under the operational program and measures to support innovation under a special regulation and the Innovation Fund established under a special regulation [23]. Innovative enterprise is an enterprise which in its activities is based primarily on an innovation strategy. It is characterized by a high share of innovative products in the sales structure, the use of advanced technology and innovative management. The structural features of an innovative enterprise are high share of investment in research, know-how, product preparation and technology. In addition to the positive benefits of innovation, companies may also face the impact of innovation barriers that may limit innovation activity [24]. In the context of innovation, the basic task of the strategy is to determine the future image of the company through goals and innovative practices. The basic groups of strategic goals of innovation include minimization of fixed costs (investments), increasing the added value of products and services, reducing production costs. Marketing innovation means the introduction of a new marketing method or methods. These methods may include changes related to the design of the product or its packaging, or the promotion of the product and its location, but also include new pricing and service methods. The aim of marketing innovation can be to increase the attractiveness of products and services, or to enter new markets. What we no longer consider a marketing innovation are, for example, seasonal changes, advertising or publicity, unless it is an advertisement or advertisement that is first introduced and based on the use of a new media medium.

\section{Methods}

Innovation is important not only from the point of view of individual specific companies, but also from a global point of view. The level of innovation in individual companies creates an overall position in the field of innovation at the national, transnational and global level. One of the tools that provides a comparative assessment of the research and innovation performance in EU countries is the European Innovation Scoreboard [25]. The research is based on secondary findings from the European Innovation Scoreboard and from the Statistical Office of the Slovak Republic [26]. In the following part of the paper we analyze the development of Innovation index in Slovakia in the years 2012-2019 (Table 1) and Share of enterprises with innovation activity from the total number of enterprises in industry and selected services available from the Statistical Office of the Slovak Republic in 2012-2018 (Table 2). In the Results and Discussion section, we analyze the data from Table 1 and Table 2 using descriptive statistics in aim to make these data clear by graphical means.

We set 2 research questions:

Research question 1: What is the development of the Innovation Index in Slovakia?

Research question 2: What is the development of the structure of companies with innovation activity by size in Slovakia? 
Table 1. Innovation index of Slovakia

\begin{tabular}{|c|c|}
\hline Year & Score \\
\hline 2019 & 72,48 \\
\hline 2018 & 70,55 \\
\hline 2017 & 68,21 \\
\hline 2016 & 71,3 \\
\hline 2015 & 68,89 \\
\hline 2014 & 67,24 \\
\hline 2013 & 71,36 \\
\hline 2012 & 70,42 \\
\hline
\end{tabular}

Source: European Innovation Scoreboard 2020.

Table 2. Share of enterprises with innovation activity from the total number of enterprises in industry and selected services

\begin{tabular}{|c|c|c|c|c|}
\hline & $\mathbf{2 0 1 2}$ & $\mathbf{2 0 1 4}$ & $\mathbf{2 0 1 6}$ & $\mathbf{2 0 1 8}$ \\
\hline $\begin{array}{c}\text { small } \\
\text { businesses }\end{array}$ & 29,80 & 28,50 & 24,60 & 25,80 \\
\hline $\begin{array}{c}\text { medium } \\
\text { businesses }\end{array}$ & 40,00 & 37,90 & 42,70 & 39,10 \\
\hline $\begin{array}{c}\text { large } \\
\text { businesses }\end{array}$ & 62,10 & 54,70 & 60,10 & 61,10 \\
\hline
\end{tabular}

Source: The Statistical Office of the Slovak republic.

\section{Results and Discussion}

Research question 1: European Innovation Scoreboard shows individual data of innovation, one of indicator is Innovation Index, based on which individual countries are classified into 4 categories: Innovation Leader, Strong innovator, Moderate innovator and Modest innovator. Slovakia is currently based on data and various indicators identified as Moderate innovator with a score of 72.48. In comparison, at the top of this ranking and thus the top Innovation leader is Switzerland with a score of 179.73. Slovakia is in 26th place out of 37 European countries. Figure 1 shows the development of the score of the Innovation index of the Slovak republic in the years 2012-2019.

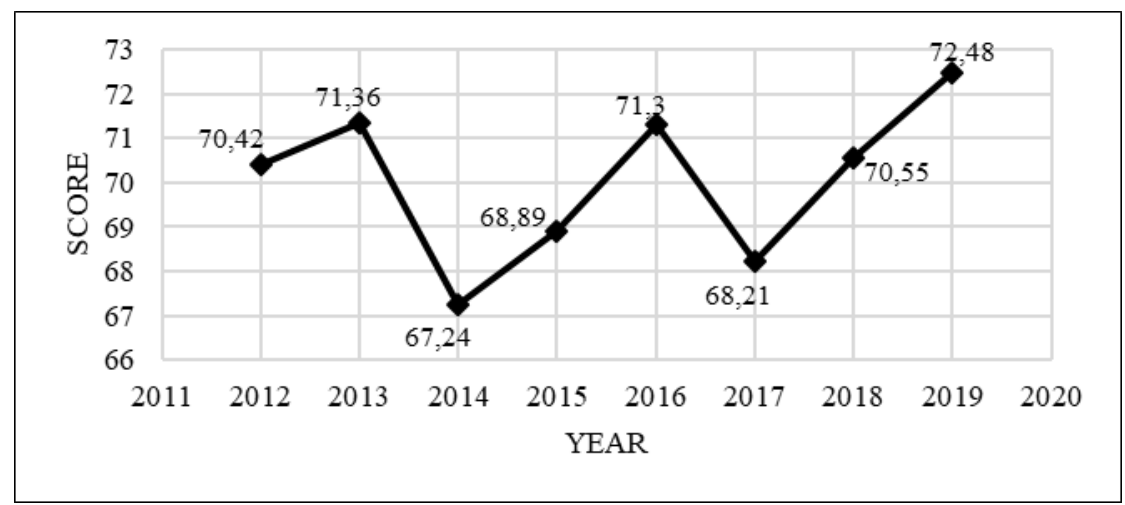

Fig. 1. Innovation index development of Slovak republic

Source: Own processing based on European Innovation Scoreboard. 
In Figure 1 we see the development of the Innovation index of the Slovak republic. In the picture we can see that for the last year, ie 2019, the index had the highest value so far. The highest decline can be seen from 2013 to 2014, followed by an increase in the index until 2016. Subsequently, there was a decline again. Since 2017, the score has grown to its current value.

Research question 2: Figure 2 shows secondary data from the Statistical Office of the Slovak republic. This is the development of the percentage of enterprises with innovation activity in Slovakia according to the size of enterprises, showing 3 basic groups of enterprises: small enterprises (10-49 employees), medium enterprises (50-249 employees) and large enterprises (250 and more employees) in years 2012-2018.

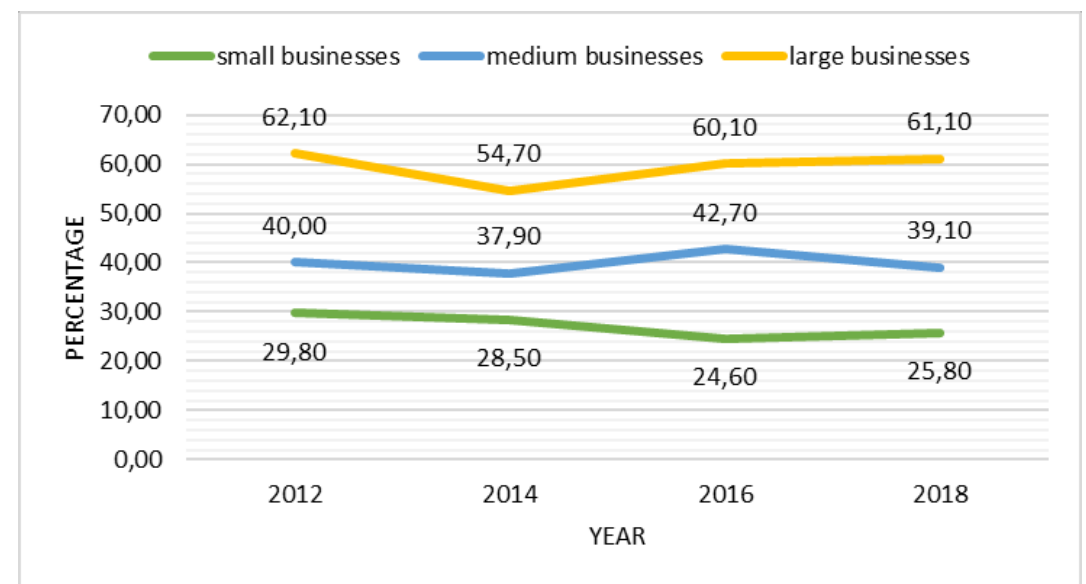

Fig. 2. Development of the percentage share of enterprises with innovation activity in Slovakia according to the size of enterprises

Source: Own processing based on the Statistical Office of the Slovak republic.

In Figure 2 we see the development of the percentage of enterprises with innovation activity in Slovakia according to the size of enterprises. Based on the data, we can see that in the years 2012-2014, the share of companies with innovation activity decreased in all types of companies. Subsequently, in the period 2014-2016, in the case of medium and large businesses, the share of enterprises with innovative activity increased and small businesses recorded a decrease in this period. In the period 2016-2018 large businesses and as well as small businesses recorded a slight increase. At medium businesses we see in this period decrease. Based on Figure 1, we can see that the innovation index did not increase continuously. In individual years, there were increases as well as decreases in this index. It is important that the innovation index of the Slovak Republic as well as other countries increases, therefore companies should include innovation activities in their business activities. Based on Figure 2, we can conclude that, despite scientific and technical progress and greater information, the last figure from 2018 is lower for all 3 groups of companies compared to the share of companies with innovation activity in 2012. The European Commission published the results of the European Innovation Scoreboard 2020 in June 2020, which shows that innovation performance continues to increase across the EU and is surpassed by the US for the second year in a row. However, more needs to be done to catch up with global innovation leaders such as South Korea, Australia and Japan. Results from the 2019 data point to opportunities for better coordination of EU innovation policies, helping Europe to improve its global competitiveness and strengthen the key role that innovation plays in overcoming the coronavirus pandemic [25]. Today's globalized and technology-influenced times provide a lot of room for innovation. This makes them among 
the most important sources of gaining a competitive advantage. The priority position in the market is given to those companies that can flexibly adapt to changing conditions and those that are interested in the field of innovation. Thanks to innovation, work is becoming more efficient, products are being developed and new products are being produced. The quality management requires effective innovation in the enterprise. A quick and flexible response to changing customer needs is also important. In recent years, the business environment has undergone significant changes. In addition to the traditional excess of supply over demand, the degree of globalization of the competitive environment is constantly increasing. Therefore, the efforts of many companies at present are not only focused on economy, but also on the development of their revenues by offering the customer extra added value. One way that may represent the full potential of this is the expansion of customer relationships. Limit our research is to use on the secondary dats of 2018, which are relatively active, but only one currently that are available. Another limit to research is the use of descriptive statistics. The main recommendation for further research is to examine the causes of declines in individual values between years, as well as suggestions and ways to improve the innovative position of companies.

\section{Conclusion}

If a company wants to be successful today, it is essential that it monitors the competition and adapts to new trends. Innovations are important in the context of the current situation in the market environment. Creating the right innovation strategy means ensuring that innovation in the company is long-term and effective. The innovation strategy needs to be created and integrated into various parts of the company and used to manage and develop the company's innovation performance. The aim of paper was to point out the theoretical basis and to analyze the available data on innovation in Slovakia. We analyzed the development of Innovation index of Slovakia and we could see that the innovation index did not have a continuous increase, because in individual years there were increases as well as decreases of this index. Slovakia is currently identified as Moderate innovator with a score of 72.48 and Slovakia is in 26th place out of 37 European countries. We then analyzed Development of the percentage share of enterprises with innovation activity in Slovakia according to the size of enterprises. Data show that the last figure from 2018 is lower for all 3 groups of enterprises compared to the share of enterprises with innovation activity in 2012. Businesses as well as whole countries should focus on increasing innovation activities by incorporating innovation activities into their business activities. In order for a company to be successful and keep pace with the market and provide its customers with the best products and services, it must constantly innovate. It's not just about innovating the products and services it offers businesses, but also about innovating processes, strategies, plans, and many other business-related things.

\section{Acknowledgment}

This paper is an output of scientific project VEGA no. 1/0718/18: The impact of psychographic aspects of pricing on the marketing strategy of companies across products and markets. 


\section{References}

1. M. Nadanyiova, The Customer Satisfaction with Services Railway Company Cargo Slovakia as a Factor of Competitiveness. Proceedings of the 18th International Conference on Transport Means Location, pp.120-124 (2014)

2. L. Michalkova, K. Frajtova Michalikova, A. Tănase, Factor analysis and its application in innovation management within manufacturing enterprises in Romania. Ekonomickomanazerske spektrum, 13(2), 37-45 (2019)

3. M. Durica, L. Svabova, Improvement of Company Marketing Strategy Based on Google Search Results Analysis. Procedia Economics and Finance, 26, 454-460 (2015)

4. M. Jedlicka, Marketingove strategie. Trnava: Univerzita sv. Cyrila a Metoda v Trnave (2006)

5. V. Trommsdorff, F. Steinhoff, Marketing inovaci. Praha: CH Beck (2009)

6. S. Adisak, Logistics service innovation for business growth: a case study of logistics service entrepreneurs. Polish Journal of Management Studies, 21(1), 394-407 (2020)

7. G. A. Pazilov, L. A. Bimendiyeva, N. P. Ivashchenko, A. N. Aitymbetova, Textile industry: issues of managing the growth of innovative activity in enterprises. Polish Journal of Management Studies, 21(1), 297-315 (2020)

8. I. Chambers, D. Gray, D. Hall, Business studies. Harlow: Pearson Education (2010)

9. A. Krizanova, The current possition and perspecives of the integrated transport systems in Slovak republic. Eksploatacja i Niezawodnosc - Maintenance and Reliability, 4, 25 27 (2008)

10. J. Kliestikova, A. Krizanova, T. Corejova, P. Kral, E. Spuchlakova, Subsidies to increase remote pollution?. Science and Engineering Ethics, 24(2), 755-767 (2018)

11. P. Kotler, Marketing Management. Praha: Grada (2013)

12. D. Lesakova, Strategicky marketing. Bratislava: Sprint (2014)

13. N. Kumar, Marketing jako strategie vedouci k uspechu. Praha: Grada (2008)

14. J. Majerova, T. Kliestik, Brand valuation as an immanent component of brand value building and managing. Procedia Economics and Finance, 26, 546-552 (2015)

15. M. Nadanyiova, Neuromarketing - An opportunity or a threat?. Communications Scientific letters of the University of Zilina, 19(4), 90-94 (2017)

16. P. Durana, A. Zauskova, L. Vagner, S. Zadnanova, Earnings drivers of Slovak manufacturers: Efficiency assessment of innovation management. Applied Sciences, 10(12), 4251 (2020)

17. K. Valaskova, J. Kliestikova, A. Krizanova, Consumer perception of private label products: an empirical research. Journal of Competitiveness, 10(3), 149-163 (2018)

18. OECD/Eurostat (2019), Oslo Manual 2018: Guidelines for Collecting, Reporting and Using Data on Innovation, 4th Edition, The Measurement of Scientific, Technological and Innovation Activities, OECD Publishing, Paris/Eurostat, Luxembourg.

19. P. Durana, K. Valaskova, L. Vagner, S. Zadnanova, I. Podhorska, A. Siekelova, Disclosure of strategic managers' factotum: behavioral incentives of innovative business. International Journal of Financial Studies, 8, 17 (2020)

20. A. Krizanova, J. Majerova, The proposal of activities of pricing policy in the process of building and managing brand value in Slovak Republic. Proceedings of the 2013 international conference on information, business and education technology (ICIBET 2013), pp.416-419 (2013)

21. A. Krizanova, L. Gajanova, M. Nadanyiova, Design of a CRM Level and Performance Measurement Model. Sustainability,10(7) 2567 (2018) 
22. M. Zabolotniaia, Z. Cheng, Z. Dacko-Pikiewicz, Influence of leadership style on employees' innovative activity. Polish Journal of Management Studies, 20(1), 478-496 (2019)

23. M. Kovac, Inovacie a technická tvorivost'. Kosice: SjF TUKE (2003)

24. A. Jakimowicz, D. Rzeczkowski, Do barriers to innovation impact changes in innovation activities of firms during business cycle? The effect of the Polish Green Island. Equilibrium. Quarterly Journal of Economics and Economic Policy, 14(4), 631676 (2019)

25. European Innovation Scoreboard 2020 [online] https://www.interactivetool.eu/ (2020)

26. The Statistical Office of the SR [online] http://www.statdat.statistics.sk (2020) 